\title{
The effect of aggregate condition during mixing on the mechanical properties of oil palm shell (OPS) concrete
}

\author{
Delsye Teo Ching Lee ${ }^{1, a}$ and Tan Suet Lee ${ }^{1}$ \\ ${ }^{1}$ Faculty of Engineering, Universiti Malaysia Sarawak, 94300 Kota Samarahan, Sarawak, Malaysia.
}

\begin{abstract}
One of the key characteristics affecting the properties of OPS concrete is the saturation condition of the coarse aggregates used during mixing. In this current study, the effect of different aggregate saturation conditions during mixing on the slump, compressive, flexural and splitting tensile strength of OPS concrete was investigated. Three aggregate saturation conditions were employed, namely saturated-surface-dry (SSD), air-dry (AD) and sun-dry (SD). The results revealed that the SD mix had a higher slump value than AD mix and SSD mix. On the other hand, SSD mix registered better compressive, flexural and splitting tensile strength compared to the AD and SD mix. This suggests that the use of SSD aggregates is more effective in producing higher strength concretes which could be credited to the internal curing provided by the SSD aggregates.
\end{abstract}

\section{Introduction}

The re-use of waste materials in many modern construction industries as an alternative approach to create a more sustainable and cleaner environment has been gaining increased attention. In the concrete industry, the making of concrete consumes a substantial amount of natural resources. To ensure the continuous availability of these resources in the future, one feasible approach is to replace natural stone aggregates with alternative coarse aggregates.

In Malaysia, the palm oil industry is one of the largest agricultural industries. Malaysia contributes about $57.6 \%$ of the total supply of palm oil in the world [1]. Large quantities of agricultural wastes have been produced due to increased agricultural production and development of agro-based industries [2]. Oil palm shell (OPS) is a solid waste material generated during the extraction of palm oil. Past studies have shown that OPS can be successfully used as full coarse aggregate replacement to produce structural lightweight concrete [3-5].

The characteristics of natural stone aggregates and OPS aggregates are very different. One distinct difference of OPS aggregates is the high water absorption capacity and this can affect the properties of the resulting concrete produced. Consequently, the current paper presents an investigation on the effects of different OPS aggregate condition during mixing on the properties of the resulting concrete. The aggregate conditions used include saturated-surface-dry (SSD), air-dry (AD) and sun-dry (SD) conditions.

\section{Materials Used for Concrete Production and Mix Proportion}

For the production of OPS concrete, Ordinary Portland Cement (ASTM Type 1), river sand as fine aggregate, OPS as coarse aggregate and Glenium C380 Type F superplasticizer were used. The OPS aggregates were obtained locally and have water absorption value of about $21 \%$. The particle size distribution of the OPS aggregate and river sand used are shown in Figure 1 and Figure 2 respectively.

The three saturation conditions of the OPS aggregate used consisted of saturated-surface-dry (SSD), air-dry (AD) and sun-dry (SD) conditions. The SSD condition was obtained by immersing the OPS aggregates in potable water for $24 \pm 2$ hours. Then, the aggregates were dried using a large cloth until all the water on the aggregate surface was removed so that the aggregates are in SSD condition prior to concrete casting. For the AD condition, the OPS aggregates were left to air-dry in ambient laboratory conditions until the moisture content of the aggregates is in the range of $2 \%$ to $6 \%$. For the SD condition, the aggregates were left out in the open to sundry for around two weeks until the moisture content of the aggregates fall below $2 \%$.

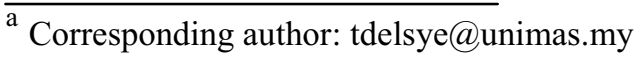


Table 1. Mix proportion of OPS concrete sample under different aggregate conditions.

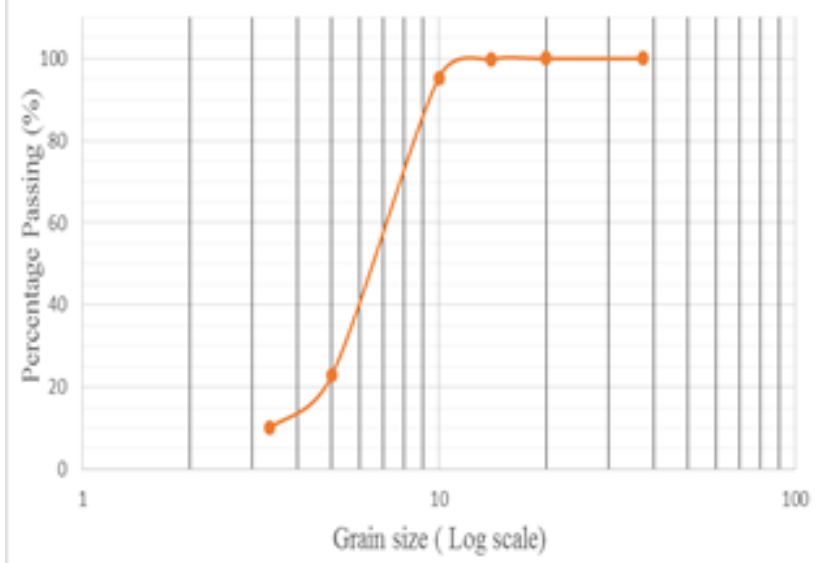

Figure 1. Particle size distribution for OPS aggregates

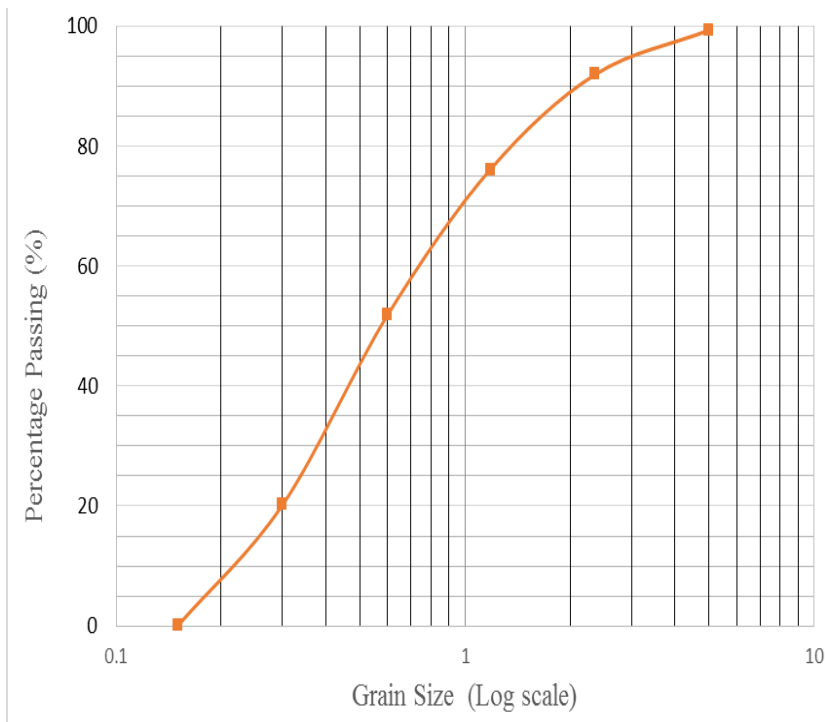

Figure 2. Particle size distribution for river sand

The mix proportion was produced using OPS as full coarse aggregate replacement and the mix was first determined using aggregates which were in SSD condition. Water adjustments were made to mixes which contained $\mathrm{AD}$ and $\mathrm{SD}$ aggregates as a means to ensure that the aggregates in these conditions do not absorb additional water from the mix. The water adjustments were made based on the moisture content of the aggregates. Table 1 shows the concrete mix proportions containing OPS aggregates with different saturation conditions. The OPS concrete mixes are called SSD mix, AD mix and SD mix hereinafter.

\begin{tabular}{|l|c|c|c|}
\hline Aggregate conditions & SSD & AD & SD \\
\hline Water to cement ratio & 0.42 & 0.42 & 0.42 \\
\hline OPS aggregate $\left(\mathrm{kg} / \mathrm{m}^{3}\right)$ & 384 & 384 & 384 \\
\hline Fine aggregate $\left(\mathrm{kg} / \mathrm{m}^{3}\right)$ & 749 & 749 & 749 \\
\hline Cement $\left(\mathrm{kg} / \mathrm{m}^{3}\right)$ & 480 & 480 & 480 \\
\hline Water $\left(\mathrm{kg} / \mathrm{m}^{3}\right)$ & 202 & 202 & 202 \\
\hline $\begin{array}{l}\text { Additional mixing water } \\
\text { (water adjustment) }\left(\mathrm{kg} / \mathrm{m}^{3}\right)\end{array}$ & - & 54 & 71 \\
\hline $\begin{array}{l}\text { Superplasticiser }(l / 100 \mathrm{~kg} \text { of } \\
\text { cement) }\end{array}$ & 1.2 & 1.2 & 1.2 \\
\hline
\end{tabular}

\section{Experimental Program}

For each OPS concrete mix, the workability of the fresh concrete was determined using the slump test in accordance with BS 1881: Part 102 [6].

For the hardened concrete, the tests conducted included the compressive strength [7], flexural strength [8] and tensile splitting strength [9]. Samples were tested at 3, 7, 28 and 56 days after being subjected to full water curing and the results were reported as an average of three tested samples. For the compressive strength test, the samples used were $100 \mathrm{~mm}$ cubes, while $100 \mathrm{~mm} \mathrm{x}$ $100 \mathrm{~mm} \times 500 \mathrm{~mm}$ beam samples and $150 \mathrm{~mm}$ (dia.) $\mathrm{x}$ $300 \mathrm{~mm}$ cylindrical samples were used for the flexural strength test and split tensile test respectively.

\section{Results and Discussion}

\subsection{Slump}

The slump values for the fresh OPS concrete under different OPS aggregate conditions are illustrated in Figure 3. From Figure 3, it can be observed that the SD mix recorded the highest slump value followed by the AD mix, while the SSD mix had the lowest slump. This suggests that the drier aggregates did not managed to fully absorb the additional water from the water adjustment added for aggregate absorption during mixing which resulted in higher initial free water content in the mix containing drier aggregates. These findings are consistent with a previous study which also showed that the concrete mix containing dry aggregates had a slightly higher slump value as compared to the concrete mix with wet aggregates [10]. 


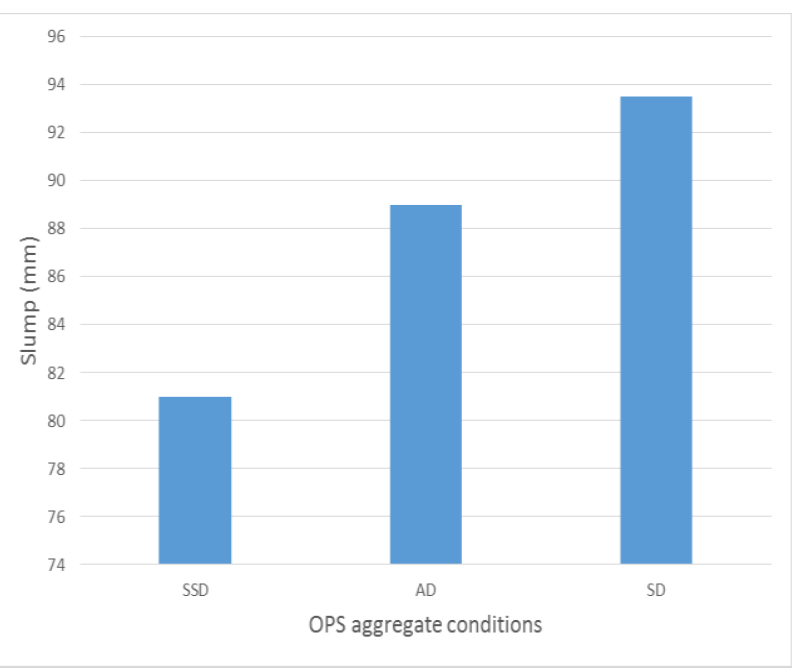

Figure 3. Slump of OPS concrete containing different aggregate conditions

\subsection{Compressive Strength}

Figure 4 presents the compressive strength development of the OPS concrete containing different aggregate conditions. The compressive strengths of the SSD mix were higher at all ages as compared to the $\mathrm{AD}$ and $\mathrm{SD}$ mix. More specifically, at an age of 28 days, the compressive strength for the SSD mix, AD mix and SD mix were $30.7 \mathrm{MPa}, 24.7 \mathrm{MPa}$ and $22.7 \mathrm{MPa}$ respectively. The compressive strength of the $\mathrm{AD}$ mix and SD mix were approximately $19.5 \%$ and $26.1 \%$ lower compared to the compressive strength of the SSD mix at 28 days.

In general, concrete strength is dependent on the amount of water contained in the concrete for hydration process. Sufficient amount of water for hydration would lead towards higher concrete strength. From this study, it can be observed that although additional water is added to the $\mathrm{AD}$ and $\mathrm{SD}$ mix during mixing, the compressive strength is still much lower compared to the mix which contained SSD aggregates. This suggests that the use of SSD aggregates is more effective in producing higher strength concretes which could be attributed to the internal curing provided by the SSD aggregates. Past studies have also shown that the cementitious hydration can be enhanced due to the process of internal curing from the internal reservoir of water absorbed by the lightweight aggregate [11,12]. Furthermore, the high absorption capacity of OPS aggregates may also strengthen the contact zone between the cement paste and the OPS through the formation of new hydrated compounds at the interface zone when SSD aggregates are used during mixing [13].



Figure 4. Compressive strength development of OPS concrete containing different aggregate conditions

\subsection{Flexural Strength}

The flexural strength of the OPS concrete containing different aggregate conditions is illustrated in Figure 5. From Figure 5, it can be observed that the flexural strength of all OPS concrete mixes continues to increase with age. As with the compressive strength results, the SSD mix registered the highest flexural strength for all ages followed by the $\mathrm{AD}$ and $\mathrm{SD}$ mix which again could be due to the effect of internal curing provided by the saturated aggregates.

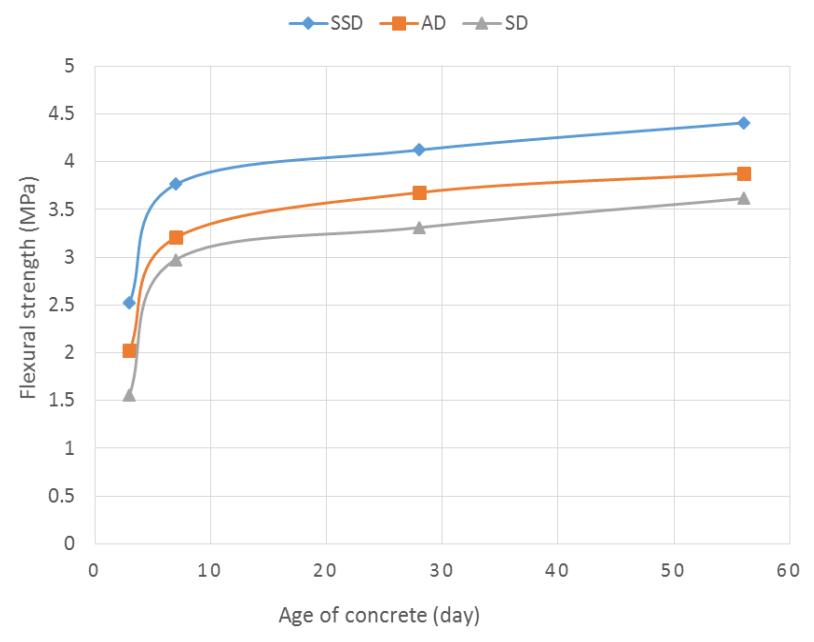

Figure 5. Flexural strength development of OPS concrete containing different aggregate conditions

In general, the flexural strength is about $10 \%$ to $20 \%$ of compressive strength of the concrete [14]. From Table 2 , it can be observed that the ratio of flexural to compressive strength for all OPS concrete containing different aggregate saturation is in the range of $12.7 \%$ to $16.9 \%$ which is in close agreement with that of conventional concrete. 
Table 2. Percentage of flexural strength to compressive strength

\begin{tabular}{|c|c|c|c|c|}
\hline \multirow{2}{*}{$\begin{array}{c}\text { Aggregate } \\
\text { condition }\end{array}$} & $\begin{array}{c}\text { Testing } \\
\text { age } \\
\text { (days) }\end{array}$ & $\begin{array}{c}\text { Compressive } \\
\text { strength } \\
\text { (MPa) }\end{array}$ & $\begin{array}{c}\text { Flexural } \\
\text { strength } \\
\text { (MPa) }\end{array}$ & $\begin{array}{c}\text { Flexural to } \\
\text { compressive } \\
\text { strength (\%) }\end{array}$ \\
\hline \multirow{4}{*}{ SSD } & 3 & 18.3 & 2.5 & 13.7 \\
\cline { 2 - 5 } & 7 & 25.2 & 3.8 & 15.1 \\
\cline { 2 - 5 } & 28 & 30.7 & 4.1 & 13.4 \\
\cline { 2 - 5 } & 56 & 34.7 & 4.4 & 12.7 \\
\hline \multirow{4}{*}{ AD } & 3 & 11.8 & 2.0 & 16.9 \\
\cline { 2 - 5 } & 7 & 20.1 & 3.2 & 15.9 \\
\cline { 2 - 5 } & 28 & 24.7 & 3.7 & 15.0 \\
\cline { 2 - 5 } & 56 & 27.3 & 3.9 & 14.3 \\
\hline \multirow{4}{*}{ SD } & 3 & 9.9 & 1.6 & 16.2 \\
\cline { 2 - 5 } & 7 & 17.8 & 3.0 & 16.9 \\
\cline { 2 - 5 } & 28 & 22.7 & 3.3 & 14.5 \\
\cline { 2 - 5 } & 56 & 25.9 & 3.6 & 13.9 \\
\hline
\end{tabular}

\subsection{Splitting Tensile Strength}

Figure 6 shows the splitting tensile strength of OPS concrete at different ages under different aggregate conditions. Again, it can be observed that the concrete mix containing SSD aggregates recorded the highest splitting tensile strength followed by the mixes containing $\mathrm{AD}$ and $\mathrm{SD}$ aggregates respectively at all ages of testing.



Figure 6. Splitting tensile strength development of OPS concrete containing different aggregate conditions

Table 3 shows the ratio of tensile splitting strength to compressive strength. Generally, for conventional concretes, the tensile splitting strength is about $8 \%$ to $12 \%$ of the compressive strength [15]. From Table 3, it can be seen that the splitting tensile strength is in the range of about $6.5 \%$ to $8.5 \%$, which is slightly lower compared to that of conventional concretes.

Table 3. Percentage of splitting tensile strength to compressive strength

\begin{tabular}{|c|c|c|c|c|}
\hline $\begin{array}{l}\text { Aggregate } \\
\text { condition }\end{array}$ & $\begin{array}{c}\text { Testing } \\
\text { age } \\
\text { (days) }\end{array}$ & $\begin{array}{c}\text { Compressive } \\
\text { strength } \\
\text { (MPa) }\end{array}$ & $\begin{array}{l}\text { Splitting } \\
\text { tensile } \\
\text { strength } \\
\text { (MPa) }\end{array}$ & $\begin{array}{l}\text { Splitting } \\
\text { tensile } \\
\text { strength to } \\
\text { compressive } \\
\text { strength }(\%)\end{array}$ \\
\hline \multirow{4}{*}{ SSD } & 3 & 18.3 & 1.4 & 7.7 \\
\hline & 7 & 25.2 & 1.8 & 7.1 \\
\hline & 28 & 30.7 & 2.0 & 6.5 \\
\hline & 56 & 34.7 & 2.4 & 6.9 \\
\hline \multirow{4}{*}{$\mathrm{AD}$} & 3 & 11.8 & 1.0 & 8.5 \\
\hline & 7 & 20.1 & 1.5 & 7.5 \\
\hline & 28 & 24.7 & 1.9 & 7.7 \\
\hline & 56 & 27.3 & 2.2 & 8.1 \\
\hline \multirow{4}{*}{ SD } & 3 & 9.9 & 0.8 & 8.1 \\
\hline & 7 & 17.8 & 1.2 & 6.7 \\
\hline & 28 & 22.7 & 1.6 & 7.0 \\
\hline & 56 & 25.9 & 2.0 & 7.7 \\
\hline
\end{tabular}

\section{Conclusions}

In the current study, the effects of OPS aggregate conditions used during mixing on the workability and mechanical strength of concrete were investigated. Three aggregate saturation conditions were used namely saturated-surface-dry (SSD), sun-dry (SD) and air-dry (AD). Based on the results obtained from this experimental study, the main conclusions drawn are:

1. The mix containing OPS aggregates under the SD state exhibited the highest slump value followed by the mix containing $\mathrm{AD}$ and SSD aggregates respectively. This suggests that the drier aggregates did not manage to fully absorb the additional water from the water adjustment added for aggregate absorption during mixing which resulted in higher initial free water content in the mix containing drier aggregates and therefore resulted in higher slump values.

2. The compressive strength of the SSD, AD and SD mix at the age of 28 days were $30.7 \mathrm{MPa}, 24.7 \mathrm{MPa}$ and 22.7MPa respectively. This suggests that the use of SSD aggregates is more effective in producing higher strength concretes which could be attributed to the internal curing provided by the SSD aggregates.

3. In terms of the flexural strength, the SSD mix also registered the highest strength followed by the $\mathrm{AD}$ and SD mix with values of $4.1 \mathrm{MPa}, 3.7 \mathrm{MPa}$ and $3.3 \mathrm{MPa}$ respectively at 28 days. It was determined that the ratio of flexural strength to compressive strength of concrete is 
about $12.7 \%$ to $16.9 \%$ which is in close agreement with that of conventional concrete.

4. The splitting tensile strength developed in the OPS concrete with SSD, $\mathrm{AD}$ and $\mathrm{SD}$ aggregates were $2 \mathrm{MPa}$, $1.9 \mathrm{MPa}$ and $1.6 \mathrm{MPa}$ respectively at 28 days. It was also found that the splitting tensile strengths of the OPS concrete were about $6.5 \%$ to $8.5 \%$ of the respective compressive strengths.

\section{Acknowledgement}

The authors would like to thank Universiti Malaysia Sarawak (UNIMAS) for providing financial support to present these findings.

\section{References}

1. Z. Ahmad, H.M. Saman, P.M. Tahir, Oil palm trunk fiber as a bio-waste resource for concrete reinforcement, International Journal of Mechanical and Materials Engineering, 5(2), 199-207 (2010)

2. S. Chandra, Waste materials used in concrete manufacturing (Noyes Publications, U.S.A, 1997)

3. M.A. Mannan, C. Ganapathy, Long-term strengths of concrete with oil palm shell as coarse aggregate, Cement and Concrete Research, 31(9), 1319-1321 (2001)

4. D.C.L. Teo, M.A. Mannan, V.J. Kurian, Structural concrete using oil palm shell (OPS) as lightweight aggregate. Turkish Journal of Engineering and Environmental Sciences, 30(4), 251-257 (2006)

5. D.C.L. Teo, M.A. Mannan, V.J. Kurian, Lightweight concrete made from oil palm shell (OPS): Structural bond and durability properties, Building and Environment, 42(7), 2614-2621 (2007)

6. BS 1881: Part 102, Testing Concrete. Method for determination of slump (British Standard Institution, London, 1983)

7. BS 1881: Part 116, Testing Concrete. Method for determination of compressive strength of concrete cubes (British Standard Institution, London, 1983)

8. BS EN 12390: Part 5, Testing Hardened Concrete. Flexural strength of test specimens (British Standard Institution, London, 2009)

9. BS 1881: Part 117, Testing Concrete. Method for determination of tensile splitting strength (British Standard Institution, London, 1983)

10. A.M. Alhozaimy, Effect of Absorption of Limestone Aggregates on Strength and Slump Loss of Concrete, Cement and Concrete Research, 31(7), 470-473 (2009)

11. A. Bentur, S. Igarashi, K. Kovler, Prevention of Autogenous Shrinkage in High Strength Concrete by Internal Curing using Wet Lightweight Aggregates, Cement and Concrete Research, 31(11), 1587-1591 (2001)

12. H. Al-Khaiat, M.N. Haque, Effect of Initial Curing on Early Strength and Physical Properties of a
Lightweight Concrete, Cement and Concrete Research, 28(6), 859-866 (1998)

13. D.C.L. Teo, M.A. Mannan, V.J. Kurian, Durability of lightweight OPS concrete under different curing conditions, Materials and Structures, 43(1), 1-13 (2010)

14. National Ready Mixed Concrete Association (2000), Flexural strength concrete. Retrieved 5 March 2015 from http://www.nrmca.org/aboutconcrete/cips/16p.pdf

15. S.H. Kosmatka, B. Kerkhoff, W.C. Panarese, Design and control of concrete mixtures. 14th ed. USA: Portland Cement Association (2002) 